\title{
Salience Effects in the North-West of England
}

\author{
Sandra Jansen (Brighton)
}

\begin{abstract}
The question of how we can define salience, what properties it includes and how we can quantify it have been discussed widely over the past thirty years but we still have more questions than answers about this phenomenon, e. g. not only how salience arises, but also how we can define it. However, despite the lack of a clear definition, salience is often taken into account as an explanatory factor in language change. The scientific discourse on salience has in most cases revolved around phonetic features, while hardly any variables on other linguistic levels have been investigated in terms of their salience. Hence, one goal of this paper is to argue for an expanded view of salience in the sociolinguistic context.

This article investigates the variation and change of two groups of variables in Carlisle, an urban speech community in the north west of England. I analyse the variable (TH) and in particular the replacement of $/ \theta /$ with [f] which is widely known as TH-fronting. The use of three discourse markers is also examined. Both groups of features will then be discussed in the light of sociolinguistic salience.
\end{abstract}

\section{A theoretical account of salience}

A broad definition of salience refers to the fact that linguistic properties can be perceptually prominent to language users. However, the concept of salience is highly debatable. Meyerhoff (2006: 71) criticises the term salience as "a maddeningly under-defined term when used in sociolinguistics" and Hickey (2000: 57) comments that salience "is notoriously difficult to quantify." Indeed, we are far from identifying why certain features are salient while other linguistic features lack salience. Only for phonetic/phonological features have any promising approaches been suggested which might make it possible to quantify and explain salience on this linguistic level. Recent evidence suggests that a high frequency of occurrence in a variety does not necessarily make a feature salient. On the contrary, features of low frequency are more likely to carry salience (cf. Podesva 2011; Rácz 2012a, b).

Labov (1972) categorises linguistic features according to their awareness in a community, i. e. indicators, markers and stereotypes. Indicators show only limited style shifting, while markers are subject to it. The comparison of indicators and markers in terms of awareness shows that speakers are usually not aware of linguistic variation in indicators, while markers are sometimes commented on, and style shifting in markers points to an awareness of the variation. For example, in the sociolinguistic interviews he conducted in Norwich, Trudgill (1986: 7-11) notes that he altered some linguistic features in some of the interviews. While he accommodates his use of T-glottaling to the interlocutor, his variant use of the variable (a:) is fairly constant and does not conform to the use of this feature by the interlocutor. Trudgill suggests that the variable (T) must be what Labov defines as a marker, while (a:) is an indicator in Norwich English. Stereotypes, on the other hand, are widely recognised in the speech community; speakers comment on them and impersonations include these features. 
According to Hickey (2000), markers are more likely to play important roles in language change processes than indicators since they carry more salience. Rácz (2012a: 59) summarises the two main theoretical positions on how indicators and markers interrelate with salience:

Most authors regard salience as a prerequisite for a marker, while others see it as an additional property that markers might have. There is a certain amount of confusion over its source as well; some imply that salient variables are selected as markers; others suggest that a variable becomes salient when it is selected as a marker.

Focussing on dialect contact situations, Trudgill (1986: 11) bases his analysis of salience on Labov's distinction between markers and indicators. He cites various properties which categorise a feature as a marker:

1. an overtly stigmatised variant

2. a high-prestige variant

3. a variable undergoing change

4. phonetic distance

5. phonological contrast.

For Trudgill, salience is an additional extralinguistic property. Rácz (2012a: 59) strongly rejects this idea. He argues that in Trudgill's model, "salience (i) is not the source of the distinction between indicators and markers, or, indeed, different types of linguistic variables in general, and (ii) is an additional property with an external basis."

Similar to Trudgill, Hickey (2000: 62-67) provides a list of possible triggers for salience. He does however emphasise that none of these factors can be given more importance than others and that they can co-occur. His list of factors includes acoustic prominence, homophonic merger, system conformity, deletion and insertion, grammatical restructuring, openness of word class, the loss of vernacular features and retention of phonetically conditioned realisations. Features are salient when they are local and are in contrast to a more supraregional or standard property. Rácz (2012a: 62) does not provide a list of possible triggers for salience as he argues that "the salience of a variable comes from its patterning in use: some variables are more surprising for speakers of a different dialect, and, consequently, carry social indexation more easily." Nevertheless, though the approaches by Hickey (2000) and Rácz (2012a) differ in that Rácz does not provide specific properties which might prompt salience, they have in common that the linguistic contrast between local and regional/standard-like features is emphasised as important for observing salience.

Kerswill and Williams (2002) take Trudgill's model of salience as the starting point for the development of a model which takes salience into account as a possible factor in language change. Their model of salience comprises three components:

- A particular linguistic phenomenon, e. g. the diffusion of forms from one variety to another where salience is seen as a cause of this change.

- Language-internal properties (e. g. phonological contrast, semantic transparency, syntactic environment).

- Extra-linguistic factors (e.g. cognitive, pragmatic, socio-psychological, sociodemographic) which are linked with the linguistic feature undergoing change.

Social and language-internal factors are important in their approach to explain salience, e. g. stark phonetic contrast. However, internal factors are only a prerequisite for features to become salient. 
Auer, Barden and Grosskopf (1998) observe changes in the speech of individuals in a longterm dialect contact situation. They choose various factors mentioned by Schirmunski and Trudgill and divide them into subjective and objective aspects: articulatory distance, areal distribution, phonemicity, continuous vs. dichotomous structure, lexicalisation as objective criteria and code-switching, representation in writing and stereotyping as subjective criteria. One main finding is that salience cannot be reduced to single factors but rather it is a complex process; e. g., salience does not seem to have an influence on strong accent features in their case study but only on features they classify as weak forms. Hence, Auer, Barden and Grosskopf (ibd.: 184) come to the conclusion that "subjective and objective parameters in determining salience are therefore not mutually predictive." Based on the results of the case study, Auer, Barden and Grosskopf (ibd.: 168) criticise Schirmunski's (1928/29) as well as Trudgill's (1986) concept in that salience in the two processes of levelling and diffusion are not analysed separately.

Podesva (2011: 27f.) dissects the social meaning of variants on the suprasegmental level, i. e. intonation patterns. He claims that variants can carry social meaning as long as they are salient. In his data set, this salience can occur in (at least) three ways:

1) metalinguistic comments;

2) prominence of infrequent variants because of their unexpected occurrence;

3) (intonational) contours that are sufficiently divergent.

Podesva gives the example of Heath, a doctor who is recorded in his professional and private environment. Heath uses rising intonation when he explains medical details to his patients but does not use this variant when talking to his friends. Podesva argues that Heath employs this variant to construct his "caring doctor" persona. Here, Podesva draws on Trudgill's assumptions about (phonetic) distance and (phonological) contrast. However, there is the problem about the term sufficiently divergent as this is not a unit which can be measured.

Llamas, Watt and Johnson (2009) investigate the effect of salience in a community where a hybrid identity construction is the case, i. e. Berwick-upon-Tweed, an English town on the border of Scotland. The dialect of this community shares many features with the rural Northumbrian dialect as well as East Central Scots. The authors claim that coda $/ \mathrm{r} / \mathrm{carries}$ extra strong salience in the border communities but they also mention the vagueness of the term phonetic distance which Trudgill uses in his model of salience. They find that phonetic distance is possibly applicable for $/ \mathrm{r} /$ as a way of identifying salience; however, for vowels this category is too vague. They agree with Kerswill and Williams (2002) who argue that vowels and consonants behave differently. Another point Llamas, Watt and Johnson raise is the lack of accommodation of stereotypical features as Trudgill suggests. "Overall, it appears that Trudgill's assertion that in dialect contact situations speakers modify features of their own varieties of which they are most aware is not borne out by the data presented here" (Llamas/Watt/Johnson 2009: 400).

Rácz's approach (2012a) is fairly new in that he tries to quantify sociolinguistic salience by applying probabilistic methods. As most other researchers, he restricts the analysis to the phonetic/phonological level. In a case study, he discusses salience based on the distribution of definite article reduction (DAR), a feature which occurs in the north of England. He claims that if speakers are surprised by the occurrence of a feature we can claim that this is indeed a sign of salience. However, he restricts his approach to be only applicable to consonants, while 
salience of vowels as "inherent parts of the speech signal" (ibd.: 76) cannot be quantified by this method. ${ }^{1}$

What is however still lacking is the analysis of sociolinguistic salience on other linguistic levels; e. g., Møller Jensen (2011) points out that salience has hardly been taken into account for morphosyntactic change processes. At the same time, pragmatic or discourse markers have scarcely been discussed in the light of this concept either.

\section{Data/Results}

The data discussed in this section originate from a larger research project conducted in Carlisle, a city in the far north west of England. The city has a population of 101,000 and is the largest conurbation in Cumbria. Carlisle is also known as the Border City. The title reflects its proximity to the Scottish border only $16 \mathrm{~km}$ away. The city's surrounding area is dominated by agriculture and the closest urban area is Tyneside some $90 \mathrm{~km}$ away. To the south-west of the city, about $50 \mathrm{~km}$ from Carlisle, lies the Lake District. To the east, the Pennines, which extend down the country, are less steep than elsewhere and make the northeast relatively accessible. The Borderlands, as well as the area west of Carlisle which stretches out to the Irish Sea (West Cumbria), are sparsely populated regions. No other urban area can be found in close proximity to the city. Hence, Carlisle is a regional centre where people commute to and from the surrounding areas (cf. Coombs 1995).

The data presented here stem from recordings of sociolinguistic interviews with people from Carlisle. My fieldwork took place in two major stages in February/March 2007 and February/March 2008 with the addition of three individual recordings in September 2009 and two further recordings in September 2010. In all, I made eighty recordings, recording a total of 109 speakers, lasting from around 25 to 90 minutes. Participants were recorded individually, in pairs and in one case, a small group.

The Carlisle dialect (henceforth $\mathrm{CE}$ ) has undergone drastic levelling and supralocalisation over the late $19^{\text {th }}$ and $20^{\text {th }}$ centuries when many local features were erased from everyday speech. However, recently we find stylized features of $\mathrm{CE}$ on commodities such as T-shirts (cf. Beal 2009) and also on Facebook (Jansen, in preparation a). In addition, features that are spreading across the country and that we find in other places, i. e. T-glottaling, TH-fronting and R-labiodentalisation, are now also attested in CE (cf. Jansen 2012).

The present sample contains data from 32 speakers from the corpus. The distribution across age and gender is displayed in Table 1. Speakers were grouped in four age cohorts: 15-25, 29$43,50-64$ and 65-86. Though it will not be discussed in detail, the speakers were identified as belonging to the working class or middle class based on their level of education and occupation.

\begin{tabular}{l|ll|l} 
& M & F & Total \\
\hline $15-25$ & 4 & 4 & 8 \\
$29-43$ & 4 & 4 & 8 \\
$50-64$ & 4 & 4 & 8 \\
$65-86$ & 4 & 4 & 8 \\
\hline Total & 16 & 16 & 32
\end{tabular}

Table 1: The distribution of speakers in this sample.

Two groups of features are discussed here. The use of TH-fronting is a variant of the phonological variable (TH) while the variable use of like, eh and like eh represents discourse

\footnotetext{
${ }^{1}$ However, Rácz (2012b) provides an experimental setting which is used to quantify salience of Hungarian hiatus resolution.
} 
variation. The former feature is one of the variants that has been spreading across varieties of English in England, whereas like and $e h$ have been described for northern English, Irish and/or Scottish varieties (cf. Beal 2008 for Northern English, Bartlett 2013 for Newcastle English, Miller 2008 for Scottish English, Luckmann 2009 and Schweinberger 2012 for Irish English). As mentioned before, salience has been discussed on the phonological level, while discourse markers have hardly been taken into account in the debate on salience.

\subsection{TH-fronting}

The first variable to be discussed here is ( $\mathrm{TH})$. As an umbrella term, TH-fronting describes the merger of $/ \theta /$ with $/ \mathrm{f} /$ and $/ ð /$ with $/ \mathrm{v} /$ where the place of articulation moves from an interdental to a labiodental position in the oral cavity. Originally a feature of Cockney, it has received a lot of attention in recent years as the feature has diffused across the country (cf. Trudgill 1988; Steele 2008; Llamas 2001; Atkinson 2011; Jansen 2012). Kerswill (2003) shows the progressive diffusion of TH-fronting from London to the west and the north on his map. Schleef and Ramsammy (2013) add a cross-dialectal view on TH-fronting in London and Edinburgh in which they show in how far language internal and social constraints differ between the two communities.

Beal (2007: 39) doubts that TH-fronting is really an innovative feature spreading to the north of England. She states that "there is a need for a more thorough search of nineteenth- and early twentieth-century sources before we conclude that 'th-fronting' was absent from Northern dialects until the late twentieth century." She hypothesises that the number of variation and change studies conducted lately could have led to more attention being given to this feature but she doubts that TH-fronting is really an innovation in many varieties. She is arguing in particular against Kerswill's (2003) and Przedlacka's (2001) hypothesis that THfronting is a late $20^{\text {th }}$ century phenomenon.

Indeed, the following quotation from Sullivan (1857: 75) about the Cumberland dialect attests that $\mathrm{TH}$-fronting is most likely not a recent innovation in this area:

The dental th is not to be found among the ancient words of the district. Kirkby Thore is still pronounced Kirkby Fure, for Thursday we find Furesday, Grisenthwaite is very generally converted into Grislefoot, and smuired appears for smothered.

In addition, evidence from toponomy can be provided. Ekwall (1918: 19) mentions that the place name Bewaldeth is recorded as Bowaldif in 1284, which is due to "the common change $\mathrm{p}>\mathrm{f}$ [which] is apparently to be assumed." 2 Thus, TH-fronting used to be a part of traditional Cumberland English inventory. From the statement above, one can derive the conclusion that if $\mathrm{TH}$-fronting occurs in $\mathrm{CE}$ in the present sample, it is not an innovation but rather a reviving of this feature. However, neither the SED data for Longtown, nor Ellis's description of the Edenside dialect gives any instances of TH-fronting. Ellis (1889: 542) comments that (TH) and (DH) "call for no remark."

Hickey explains that features can indeed recur during the linguistic history of a variety. For him, transmission, i. e. the acquisition of features during the process of first language acquisition, can vary between generations not least due to imperfect learning or dissociation:

The transmission of features across generations may be subject to shifts, indeed reversals, which have nothing to do with the relative isolation of the community. These shifts of transmission are referred to collectively in the present paper as $e b b$ and flow. One particular reason for this label

\footnotetext{
2 Similarly Armstrong et al. (1971: 119) provide examples for this sound change; e. g., Thornby is listed as Forneby (1285) and Formeby (1322) and they comment on "the common dialectal confusion between the spirants $f$ and $p$." Ferguson (1873: 149) provides the example tharf as a variant of tharth.
} 
is that frequently one has a reversal followed by a reinstatement of a feature value, hence the bidirectionality implied in $e b b$ and flow. (Hickey 2002: 1)

Hickey (2002) emphasises that unconscious awareness of a feature is an important drive in language change and that linguistic dissociation of these unconscious features from a preceding generation could indeed be the reason why ebb and flow movements are possible. We will see the extent to which TH-fronting is represented in the sample.

Figure 1 provides the distribution of TH-fronting according to age and gender. For both gender groups we notice fairly low numbers of [f] for $/ \theta /$ for older speakers but a steep increase of this between the 29-43 year old group and the youngest speakers. However, we also see that in the group of the oldest speakers there are tokens that are realised as [f]. This should not come as a complete surprise as we have pointed out before that $\mathrm{TH}$-fronting is attested in Cumberland in the $19^{\text {th }}$ century. Hence, this low frequency of [f] could be a remnant of the TH-fronting found in Cumberland in the $19^{\text {th }}$ century. Figure 2 will provide us with more information about this change.

While the young male speakers realise $/ \theta /$ as [f] in over $40 \%$ of all instances, TH-fronting occurs in only around $25 \%$ of the young female speakers. The fact that this change is led by male speakers lets us assume that we are most likely dealing with covert prestige here.

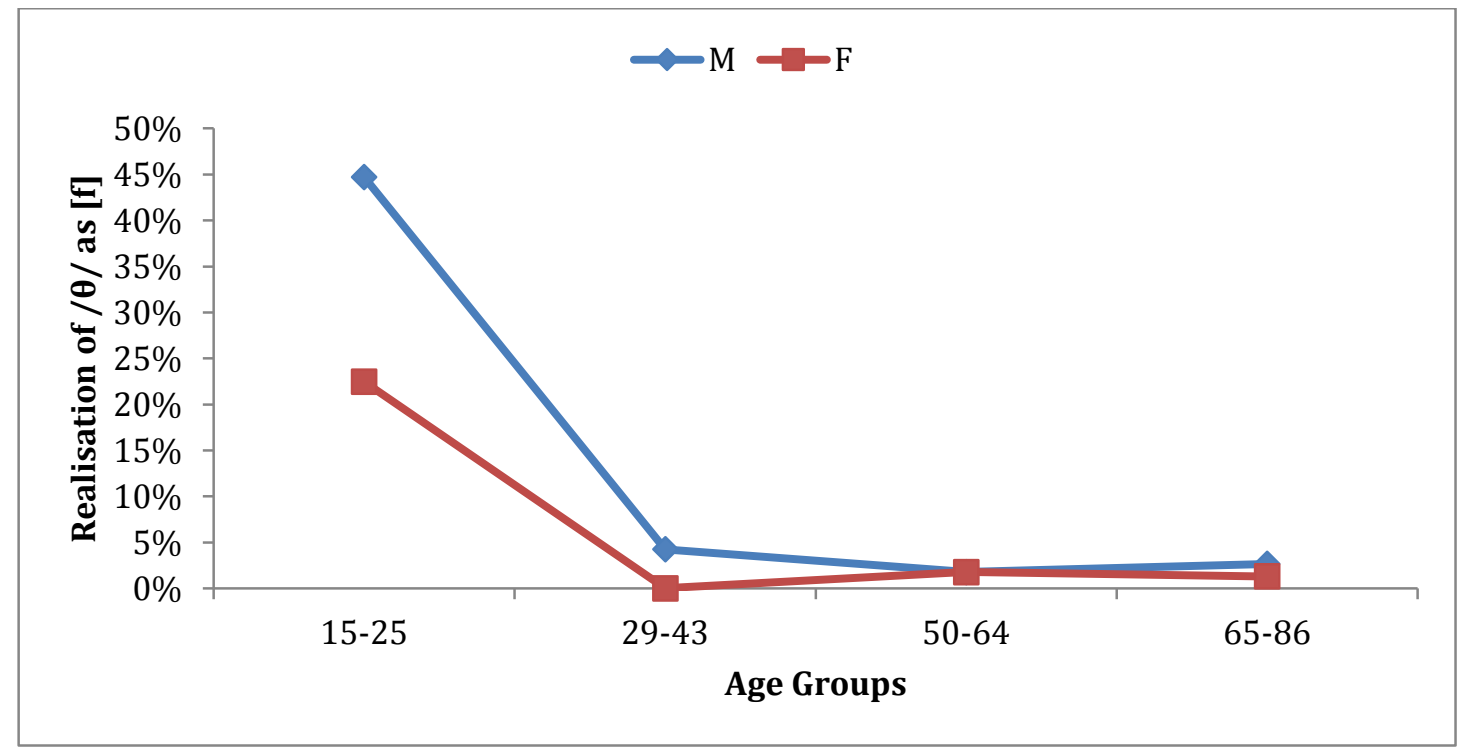

Figure 1: Distribution of TH-fronting according to age and gender. 


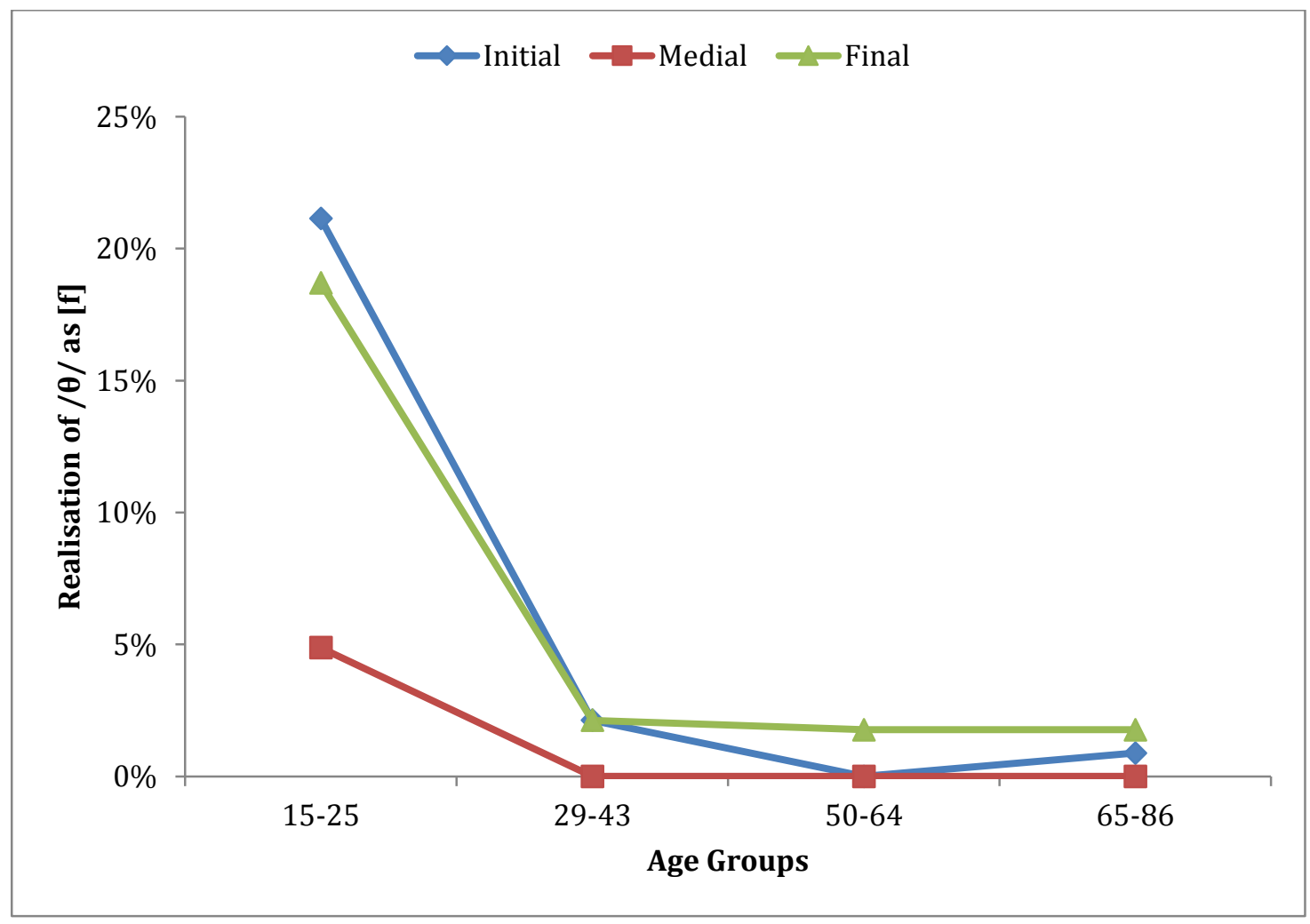

Figure 2: Distribution of TH-fronting according to position in a word across age for male speakers.

Figure 2 shows the distribution of TH-fronting according to position in the word for male speakers. While most tokens of [f] are found in word-final position for the older speakers, the highest rate of TH-fronting is found in word-initial position for young speakers. TH-fronting in word-medial position is only found in the youngest speaker group and significantly less than in word-initial and word-final positions.

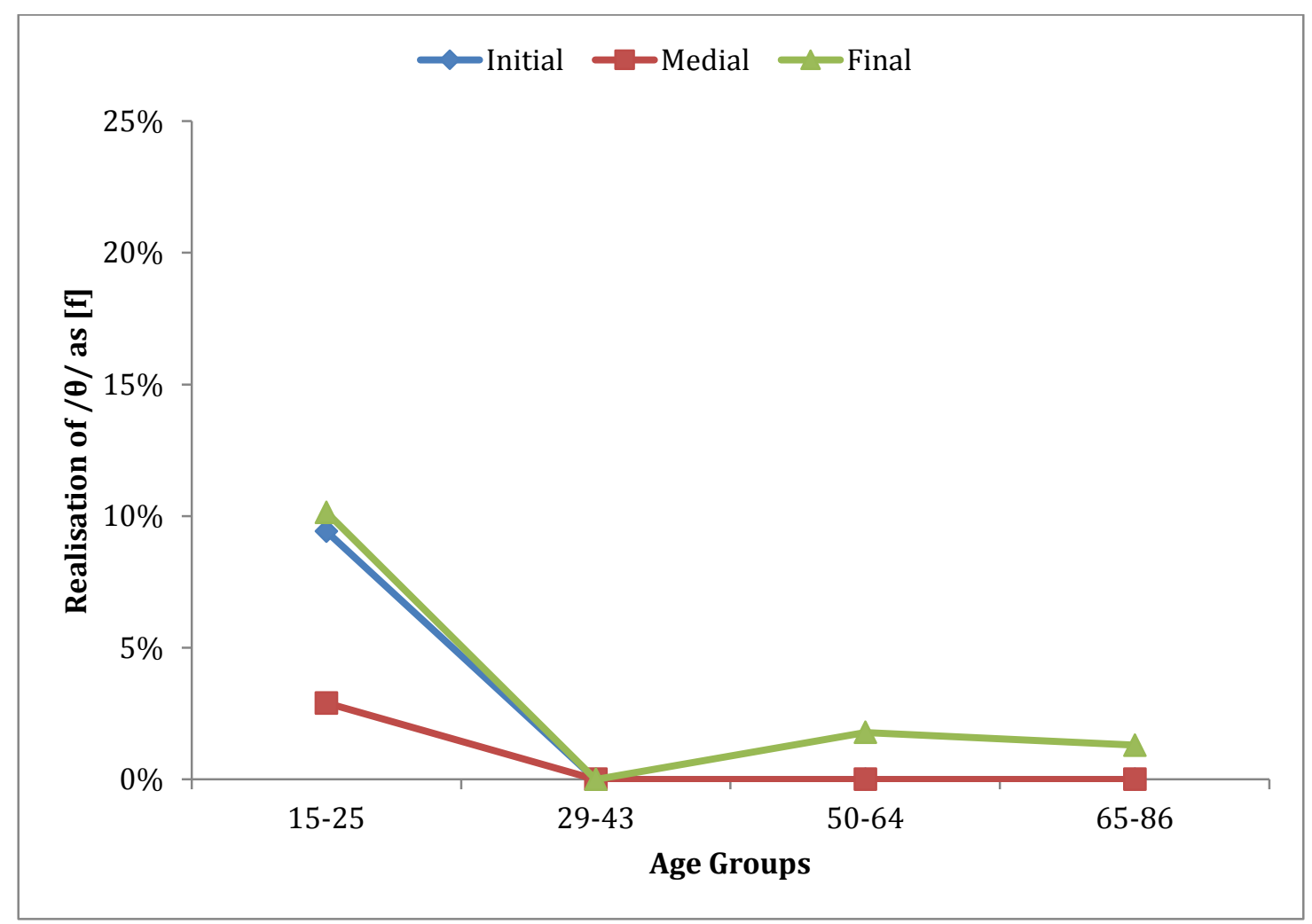

Figure 3: Distribution of TH-fronting according to position in a word across age for female speakers. 
The distribution of TH-fronting according to the position in the word is similar for female speakers (Figure 3). Figure 2 and Figure 3 show that the oldest speakers primarily use THfronting in final position and only exceptionally in initial position but never in medial position. However, the youngest age group uses TH-fronting in word-initial, medial as well as final positions. Compared to initial and final positions, TH-fronting rarely occurs in medial position; however, the position in the word is statistically not a predictor for this variant.

Even though there are similarities in the distribution of the labiodental fricative between the gender groups, the frequency of the variant [f] is significantly lower for female speakers than for male speakers. A multi regression analysis confirms that age $(p<0.01)$ and gender $(p<0.01)$ as well as social class $(p<0.01)$ are highly significant factors in this change.

For this part of the study, I used the Rbrul software package (Johnson 2013) as a statistical toolkit which runs logistic regressions taking mixed effects into account to identify predictors of language change.

Mixed effects models can take into account by-speaker and by-item correlations. They estimate between-group effects (like gender) at the same time as within-group effects (like individual speaker). They support continuous factor groups like age or lexical item as well as continuous responses (dependent variables) like vowel formant measurements. This means you can include all kinds of different factors in the same model. (Tagliamonte 2012: 138)

Thus, the advantage of the application of this statistical tool is to include random factors such as individuals and also age as a continuous variable. With more traditional tools, age has to be categorised and the individual is disregarded. The statistical model used here includes the social factors of age, gender, social class and style as well as the internal factor position and while the social factors were all statistically significant, position was not. Table 2 summarises the results of the statistical model used in this study.

\begin{tabular}{|c|c|c|c|c|}
\hline \multicolumn{5}{|c|}{ Deviance: 391.615} \\
\hline \multicolumn{5}{|l|}{ df: 6} \\
\hline \multicolumn{5}{|c|}{ Intercept: 1.074} \\
\hline \multicolumn{5}{|c|}{ Grand mean: 0.096} \\
\hline \multicolumn{5}{|c|}{ Nagelkerke $\mathbf{R}^{2}: 0.476$} \\
\hline $\begin{array}{l}\text { Applications } \\
\text { Value: } \\
\text { [f] }\end{array}$ & Factors & Log Odds & Tokens (N) & $\begin{array}{l}\text { Mean } \\
\text { Value }\end{array}$ \\
\hline $\begin{array}{l}\text { Age } \\
p<0.01\end{array}$ & $\begin{array}{l}\text { Continuous } \\
15-86\end{array}$ & $+1-0.103$ & & \\
\hline \multirow{2}{*}{$\begin{array}{l}\text { Social Class } \\
p<0.01\end{array}$} & WC & 1.246 & 454 & 0.777 \\
\hline & $\mathrm{MC}$ & -1.246 & 574 & 0.223 \\
\hline \multirow{3}{*}{$\begin{array}{l}\text { Style } \\
p=0.0349\end{array}$} & Text & 0.487 & 294 & 0.619 \\
\hline & Interview & -0.243 & 496 & 0.44 \\
\hline & Sentence list & -0.244 & 238 & 0.439 \\
\hline \multirow{2}{*}{$\begin{array}{l}\text { Gender } \\
\mathrm{p}<0.01\end{array}$} & $\mathrm{M}$ & 0.319 & 443 & 0.579 \\
\hline & $\mathrm{F}$ & -0.319 & 585 & 0.421 \\
\hline
\end{tabular}

Table 2: Rbrul output for labio-dental fricatives for all speakers.

The results of the statistical model confirm that not only younger speakers but also male speakers and working class speakers favour TH-fronting, which is again an indicator that we are dealing with a variant that carries covert prestige. 
A look at the individuals reveals a large range in the distribution of [f] (Table 3). Overall, sixteen speakers use this variant. The five speakers who use [f] in over $40 \%$ of all cases all belong to the youngest age group and all are working class (F1, M2, M4, M1 and F4). However, we also see other members of this age group hardly making use of this form (M3, F2, F3). Hence, not necessarily everyone in the youngest age group participates in this dramatic change. For other speakers outside the youngest age groups scarcely more than single instances are attested.

\begin{tabular}{|l|l|l|l|l|}
\hline Speaker & Age & Tokens / $/$ / & N [f] & \% [f] \\
\hline M3 & 15 & 36 & 1 & 2.78 \\
\hline M11 & 63 & 29 & 1 & 3.45 \\
\hline M15 & 78 & 29 & 1 & 3.45 \\
\hline F13 & 68 & 56 & 2 & 3.57 \\
\hline F2 & 23 & 27 & 1 & 3.7 \\
\hline M16 & 32 & 27 & 1 & 3.7 \\
\hline F3 & 15 & 74 & 4 & 5.41 \\
\hline M12 & 68 & 29 & 3 & 6.9 \\
\hline M9 & 53 & 27 & 2 & 7.41 \\
\hline F8 & 58 & 27 & 2 & 7.41 \\
\hline M6 & 36 & 28 & 3 & 10.71 \\
\hline F1 & 22 & 10 & 4 & 40.0 \\
\hline M2 & 25 & 32 & 15 & 46.88 \\
\hline M4 & 16 & 28 & 20 & 71.43 \\
\hline M1 & 22 & 27 & 20 & 74.07 \\
\hline F4 & 16 & 27 & 22 & 81.48 \\
\hline
\end{tabular}

Table 3: Distribution of [f] for $/ \theta /$ by individuals

The distribution according to style is presented in Figure 4. Similar to the results by Schleef and Ramsammy (2013), the social constraints in terms of style do not provide much information about the nature of the change even though we find a statistically significant difference between the occurrences of TH-fronting in the three styles: interview, text and sentence list. TH-fronting is favoured in the text passage and occurs least in the sentence list in the youngest group (see Figure 4). Even though it is puzzling that a higher rate of THfronting occurs in a more formal style than in an interview, we could argue that the speakers use this feature and consciously decide for a style shift. This result makes us assume that $\mathrm{TH}-$ fronting is indeed a marker in CE. 


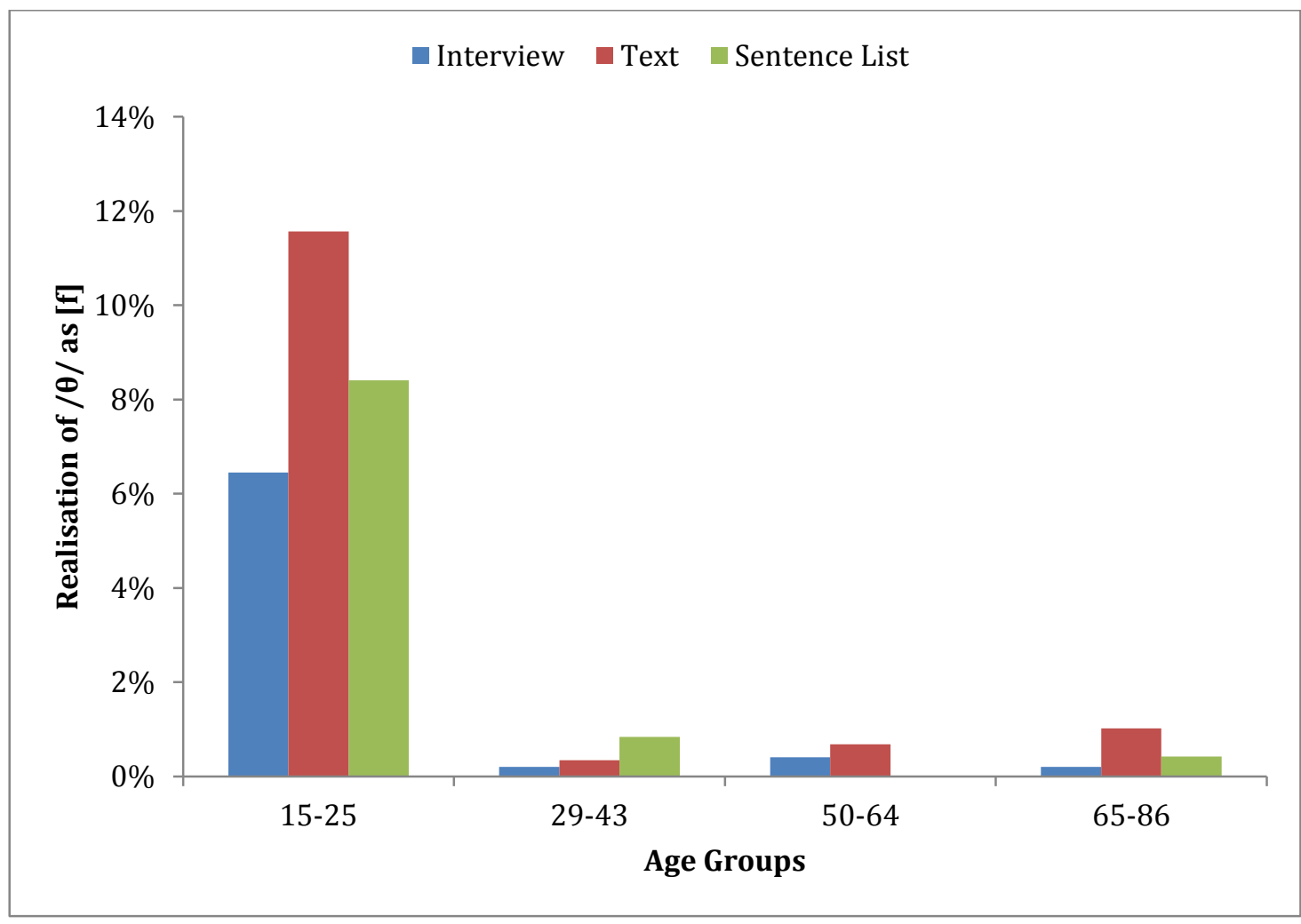

Figure 4: Distribution of TH-fronting according to style.

The distributions of TH-fronting among the speakers in Figure 1-4 provide us with additional information about the change: 1) the older speakers do not take part in this recent change but adhere to a more traditional form; 2) only the group of young speakers are obviously affected by TH-fronting due to the recent diffusional wave. ${ }^{3}$ Thus, the differential distribution across environments provides us with the evidence that this is in fact a new wave of TH-fronting, complementary to the distribution of the layer of TH-fronting already found in CE.

The very interesting finding here is that not only do young speakers use this variant, but we also find TH-fronting tokens in the other age groups. As was mentioned before, TH-fronting is traditionally attested in Cumberland. Thus, one can assume that the older speakers are using a traditional form. This view is enhanced by the fact that the older speakers mainly use it in word-final position rather than in initial or medial position. In comparison, younger speakers use the labiodental variant in word-initial position in addition to the other two positions.

This finding raises the question how the role of salience differs in a levelling process from the role of salience in a diffusional process. If a variant is declining in a variety, it is very likely that this variant disappears first from positions which potentially carry more salience. Similarly, TH-fronting is salient in word-initial position, a realisation which seems to have been part of the traditional CE inventory (cf. Sullivan's quotation) but it has disappeared from it. We suggest that $/ \theta$ / in word-final position is less salient in this levelling process; i. e., it is likely that $\mathrm{TH}$-fronting was further used in this position, even though the variant was only used sporadically.

Recently we see the arrival of the diffusional feature [f] for $/ \theta /$. Even though the language internal factor position is not statistically significant here, the results still suggest that language internal factors can affect the level of salience. The change towards TH-fronting in word-initial and word-final position is happening faster than in medial position. It could

\footnotetext{
${ }^{3}$ Though probably the use of the traditional feature and the incoming use of [f] overlap and no clear line can be drawn.
} 
therefore be the case that ( $\mathrm{TH})$ in medial position does not carry as much salience as it does in word-initial or word-final position and, therefore, speakers do not pick up the incoming variant as quickly as in a position where the degree of salience is higher.

\subsection{Discourse markers like/eh/like eh}

Turning now to the discourse markers, the linguistic situation is somewhat different in the speech community. The sentences (1) - (3) provide examples of all three variants in $\mathrm{CE}$ speech $^{4}$ :

(1) a. Me dad was a Scotchman like.

b. We wouldn't get that ahere like.

c. I love Chester like.

(2) a. And you seen them cuttin the throats and all that, eh.

b. They made a big deal of it, eh when it first opened.

c. They didn't actually bury them in the ground, eh.

(3) a. They used to come up and cuddle you as they do like eh.

b. It was a funny guy like eh.

In the sociolinguistic interviews and in questionnaires, the participants mentioned some or all three variables when I asked them what was typical of CE speech. Some comments are given in A-C. Example D is the headline of a story which was covered in the local newspaper in 2012. Due to the metalinguistic comments about these pragmatic markers and the stylization of like eh (cf. Coupland 2009), we can assume that the speakers have a conscious awareness of these variants; i. e., these forms can be classified as stereotypes in CE.

A When people put $e h$ at the end of a sentence and it's like $e h$ isn't a full stop. But they do. They'll say how's it going today eh and I'm like: Why have you said eh? Cause it's not a full stop. But they do do it.

B I mean Carlisle people tend to say things like like at the end of the sentence or eh I mean I don't know whether you've noticed that but if they're just sort of talking generally they would use the word like or $e h$ at the end.

C There's lot of people say eh or like after every sentence if you if you noticed so that's bit of a Carlisle accent eh.

D Recognise this Cumbrian tropical paradise, like eh? (News and Star 2012).

While the speakers who made the first two comments did not use either clause-final like, eh or like eh, the informant in example $\mathrm{C}$ comments on the stereotypical nature of these discourse markers and actually uses $e h$ at the end of the statement which is not part of the metalinguistic comment. The comments in $\mathrm{A}-\mathrm{C}$ also show that the three pragmatic markers seem to vary in prestige in the community. Statements $\mathrm{A}$ and $\mathrm{B}$ reveal rather negative attitudes towards these stereotypes while statement $C$ is a positive remark on these features. We can assume that even though not all speakers use them, the majority of the speech community are consciously aware of these (stigmatized) features, something which stands in contrast to the findings of TH-fronting in this variety.

Even though the number of studies analysing pragmatic markers in a variation and change framework is still comparatively low (cf. Pichler 2010), like is somewhat of an exception. Due to its functional omnipresence in English, various researchers have dedicated work to like (e.g. Daily-O'Cain 2000; Andersen 2001; Cukor-Avila 2002; Buchstaller 2004; Tagliamonte/D'Arcy 2004; D'Arcy 2005; Babieri 2009). In this paper we will focus on clausefinal like, a traditional feature which has been identified "as an emphatic device in clause-final

\footnotetext{
${ }^{4}$ The examples provided here already show functional differences between the pragmatic markers which will be discussed in another paper (Jansen in preparation b).
} 
position" (Beal 2008: 398) mainly found in northern, Scottish and Irish English. While clausefinal like in Irish English has been discussed in various studies, Bartlett (2013: 2) comments on the restricted number of studies on clause-final like in the north of England: "CFL remains unstudied within the dialects of Northern English, meaning that little is known as to its distribution, or indeed its existence, in these varieties." Indeed, studies on this pragmatic marker are sparse in the north of England.

Schweinberger's findings (2012) based on ICE Ireland suggest that clause-final like is decreasing in Irish English, while Bartlett (2013) finds a declining pattern of clause-final like in Newcastle in the NECTE corpus. However, due to the nature of the data, neither Schweinberger's nor Bartlett's study provide information about the awareness of clause-final like in the speech community. As shown in examples $\mathrm{B}$ and $\mathrm{C}$, the sociolinguistic interviews conducted in Carlisle provide us with the information that speakers of CE perceive clausefinal like as a stereotypical feature of CE. ${ }^{5}$

While clause-final like is mentioned and analysed for various places, the pragmatic marker eh has not been discussed in the northern English context. This pragmatic marker is also found in other varieties of English around the world. ${ }^{6}$ Miller (2008: 311) mentions the tag question eh for Scottish English but in the description of Northern English, Beal (2008) does not comment on $e h$. The functions of this pragmatic marker in CE have yet to be analysed; however, from the examples (2) a.-c., it becomes clear that $e h$ does not only have the function of a question tag in $\mathrm{CE}$ and that it is used in phrase-final position rather than in clause-final position. A third pragmatic marker in $\mathrm{CE}$ is like eh which has not been commented on in the literature for any other variety but should not be dismissed from this analysis.

The small number of studies on variation in pragmatic markers has partly to do with the problem of quantifying the distribution of these variables in terms of different variants. Pichler (2010) addresses the problem that even though the Principle of Accountability (Labov 1972: 71-72) is a well-established concept in variationist studies, for pragmatic variables this concept is not satisfying:

Unlike other linguistic features, discourse-pragmatic features do not occupy a fixed syntactic or segmental slot, nor is their pragmatic meaning constant; they occur in a variety of positions and take on different pragmatic meanings across different contexts of use. They are referentially and syntactically optional elements of discourse that can be omitted without necessarily altering the propositional meaning or syntactic structure of an utterance. (Pichler 2010: 588)

Here this problem cannot be solved, but nor do we claim that like, eh and like eh are variants of the same variable. Yet they seem to share some properties which will be analysed and discussed in the future (Jansen in prep. a). To quantify variation and compare the results, the frequencies are analysed as occurring per 1,000 words.

\footnotetext{
5 However, we find this feature in traditional dialects all across the north.

6 Meyerhoff (1994) has published on eh in New Zealand English. Ramisch (2007) mentions eh as discourse marker in Jersey English and there is a long-standing research history on $e h$ in Canadian English. In these studies $e h$ is always described as a stereotype of the respective variety.
} 


\begin{tabular}{|l|l|l|l|l|l|l|}
\hline & $\begin{array}{l}\text { No. of } \\
\text { tokens for } \\
\text { clause-final } \\
\text { like }\end{array}$ & $\begin{array}{l}\text { Frequency/ } \\
\mathbf{1 , 0 0 0} \text { words }\end{array}$ & $\begin{array}{l}\text { No. of } \\
\text { tokens } \\
\text { for } \\
\text { phrase- } \\
\text { final } \text { eh }\end{array}$ & $\begin{array}{l}\text { Frequency/ } \\
\mathbf{1 , 0 0 0} \text { words }\end{array}$ & $\begin{array}{l}\text { No. of } \\
\text { tokens } \\
\text { for } \\
\text { clause- } \\
\text { final like } \\
\text { eh }\end{array}$ & $\begin{array}{l}\text { Frequency/ } \\
\mathbf{1 , 0 0 0} \text { words }\end{array}$ \\
\hline $\mathbf{1 5 - 2 5}$ & 34 & 2.33068275 & 17 & 1.16534138 & 4 & 0.27419797 \\
\hline $\mathbf{2 9}-\mathbf{4 3}$ & 3 & 0.16900456 & 18 & 1.01402738 & 0 & 0 \\
\hline $\mathbf{5 0 - 6 4}$ & 6 & 0.3298697 & 33 & 1.81428336 & 3 & 0.16493485 \\
\hline $\mathbf{6 5}-\mathbf{8 6}$ & 24 & 1.12723686 & 45 & 2.11356911 & 2 & 0.09393641 \\
\hline Total & $\mathbf{6 7}$ & $\mathbf{0 . 9 3 2 9 0 0 7 6}$ & $\mathbf{1 1 3}$ & $\mathbf{1 . 5 7 3 3 9 8}$ & $\mathbf{9}$ & $\mathbf{0 . 1 2 5 3 1 5 0 3}$ \\
\hline
\end{tabular}

Table 4: Frequency of like, eh and like $e h$ in the present sample.

Table 4 provides an overview of the frequencies of the three pragmatic markers according to the four age groups in the sample. Across the sample, 67 tokens of utterance final like, 113 tokens of $e h$ and 9 tokens of like $e h$ were found.

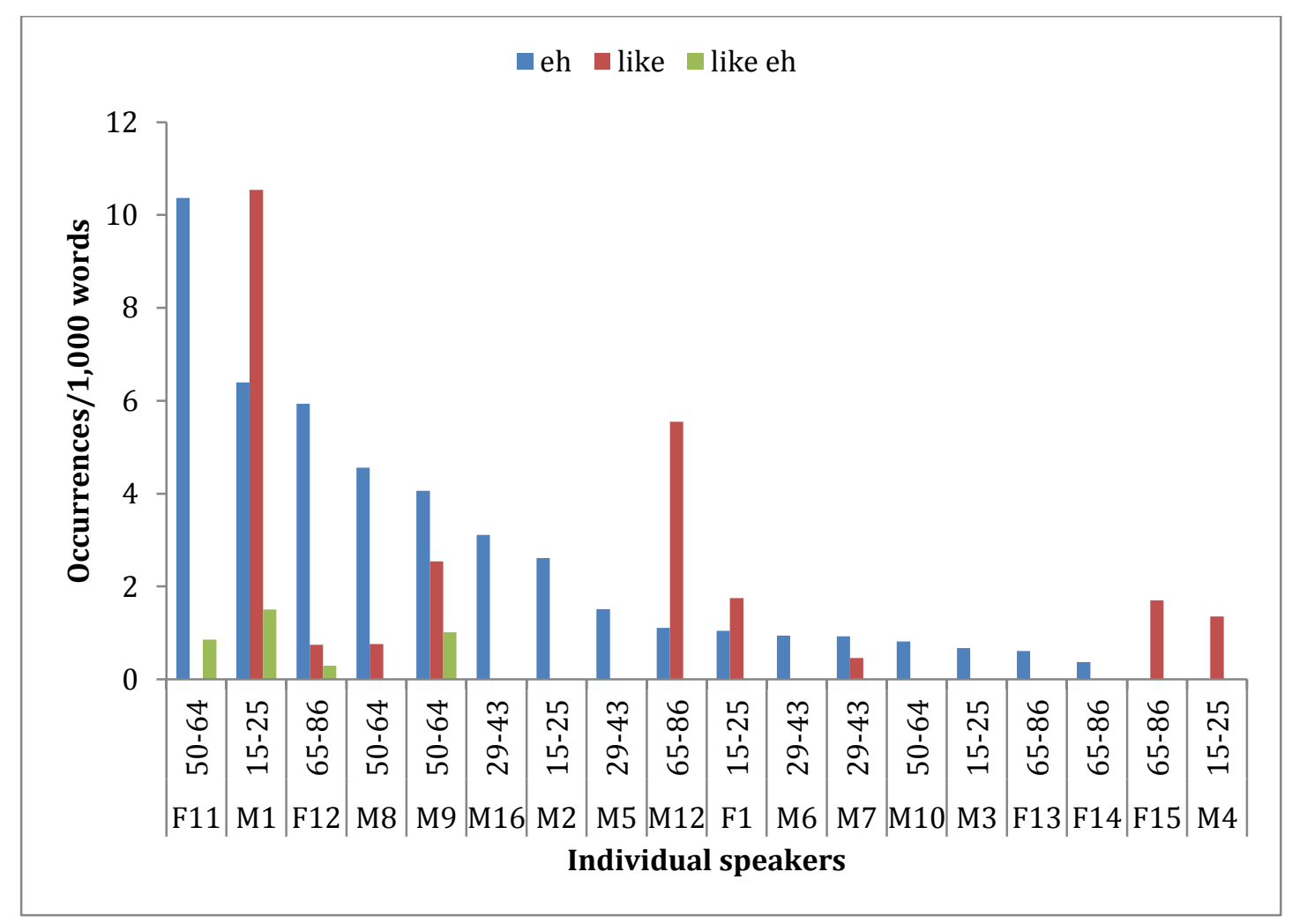

Figure 5: Distribution of eh, like and like eh by individuals (speakers who do not use the forms are not included).

A closer look at the data reveals that not all of the participants use these pragmatic markers. Figure 5 provides an overview of the 18 speakers who use one or more of the three markers. $E h$ has the widest distribution across the group, with 16 people using this form. Only four people use like eh but all of them use $e h$ relatively more frequently than other speakers. Three of the four people also use eh and like; however, people who do not use these two pragmatic markers also do not use like eh. Overall, seven informants use like and eh and nine participants use eh but not like. This distribution of the pragmatic markers might hint at an implicational scale (cf. Rickford 2004). Social class also seems to play an important role, which has to be investigated further as all but one speaker (M16) who use these forms belong to the group of working class speakers. 


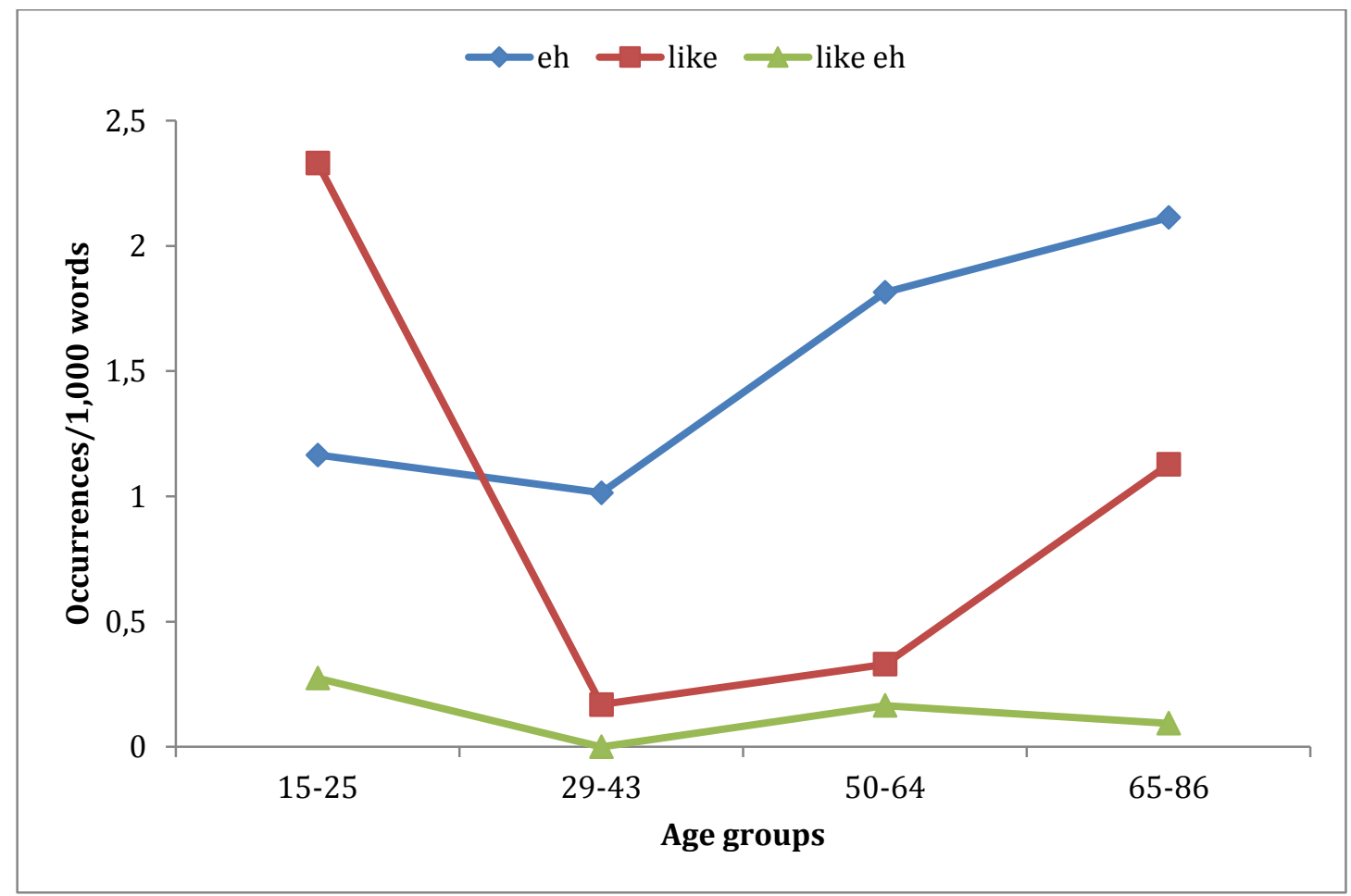

Figure 6: Distribution of the pragmatic markers like, eh and like eh across the age groups.

Figure 6 provides an overview of distribution of the three pragmatic markers in apparent time. For $e h$, we find a steady decline from 2.1 to 1.0 occurrences per 1,000 words between the age group of 65-86 and 29-43. However, between the latter group and the youngest speakers the decline slows down and in fact there is a small increase in this pragmatic marker for the youngest group.

For like, 1.12 occurrences per 1,000 words are attested for the oldest generation, which then drops to 0.33 occurrences for the 50-64 year old speakers but then bounces up to 2.3 occurrences per 1,000 words for the youngest generation and, therefore, becomes the most commonly used of all three pragmatic markers.

The data show that like eh is even more infrequent compared with the other two pragmatic particles which are not very frequent either. This could have to do with speakers identifying these markers as stereotypes of $\mathrm{CE}$ and hence, avoiding them in this interview situation; however, it could also support Podesva's (2011) and Rácz's (2012a) hypothesis that low frequency variants can be unexpected and are therefore salient for language users. 


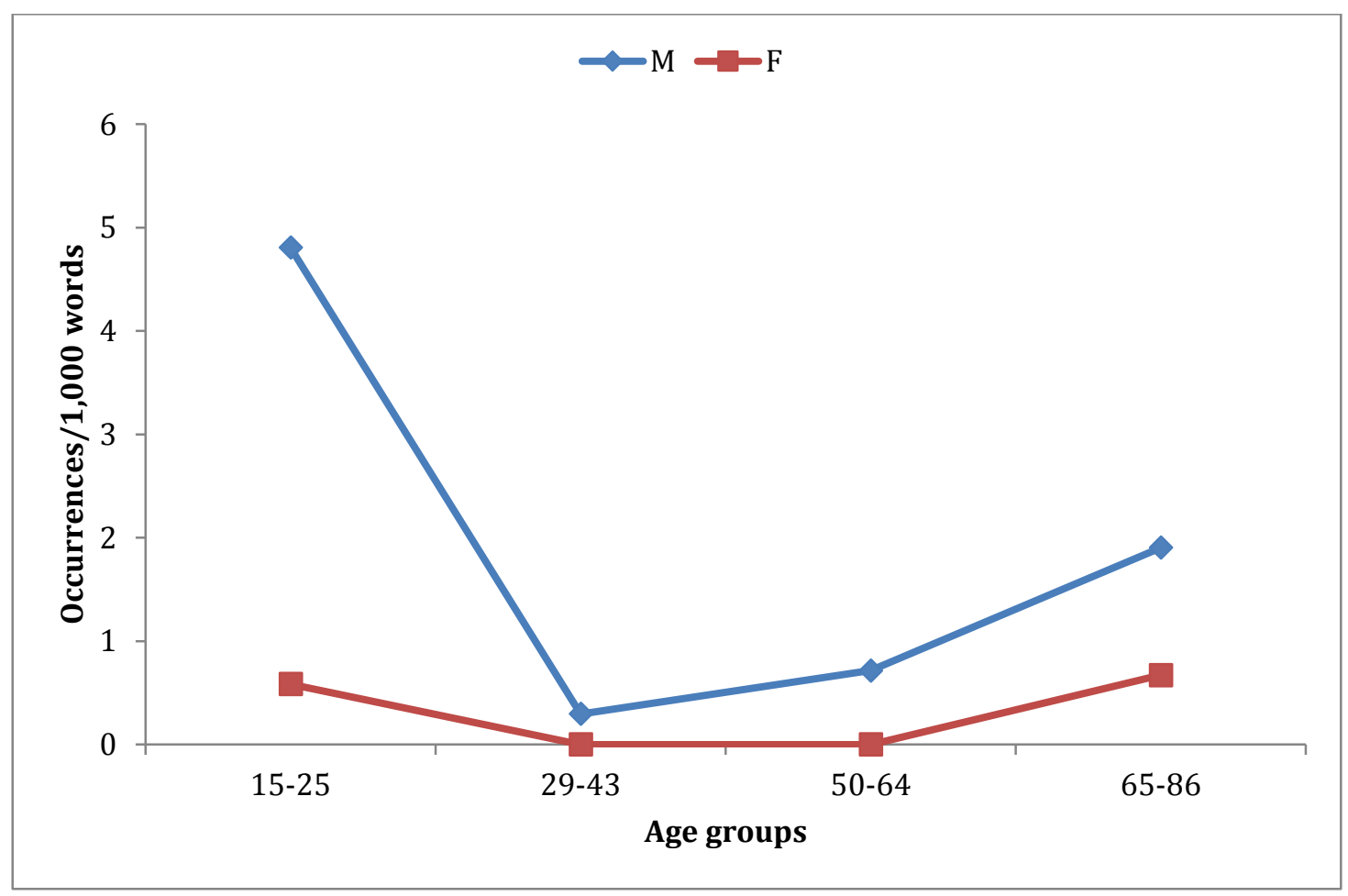

Figure 7: Distribution of the pragmatic marker like across age and gender.

Figure 7 shows that the pragmatic marker like is found in both gender groups, though the change is much more dramatically in young male speakers where the use shoots up from 0.3 to 4.8 occurrences per 1,000 words between the 29-43 year old speakers and the youngest group of male speakers. A similar pattern is observable for female speakers in this sample, though the occurrences are far lower than for male speakers. The distribution is approaching statistical significance $\left(\chi^{2}: 7.169, \mathrm{df}=3, p=0.066\right)$. Nevertheless, these results in combination with the overt comments lead to the assumption that the role of clause-final like as identity marker is strengthened in the community.

This result is a bit of a surprise as results from other varieties such as Irish English (Schweinberger 2012), Newcastle English (Bartlett 2013) and Milton Keynes/Reading/Hull (Kerswill/Williams 2002) suggest that the use of clause-final like is decreasing. In CE however, this decreasing trend is reversed and clause-final like is recycled (cf. Barnfield/Buchstaller 2010; Durham 2011). Both gender groups are affected by this change; however, the male group is leading it.

Figure 8 shows a very different pattern for $e h$. While the frequency increases for male speakers in apparent-time, the use of this pragmatic marker decreases for females, which leaves us with a cross pattern. The comparatively high number of 3.1 occurrences per 1,000 words is the result of one older female speaker who used the token 40 times. However, the downward trend is undeniable for female speakers across the four age groups. For the youngest group of female speakers, only 0.35 occurrences per 1,000 words are attested, while for the group of 50-64 year old female speakers, 1.7 words/1,000 are documented, which then is completely avoided by speakers in the group of 29-43 year old speakers. For the male speakers, the use of eh across apparent-time is increased from $0.38 / 1,000$ words for the oldest speakers to $1.9 / 1,000$ for the group of 50-64 year old speakers. The use of $e h$ then increases to $2.3 / 1,000$ words for the young male speakers. 


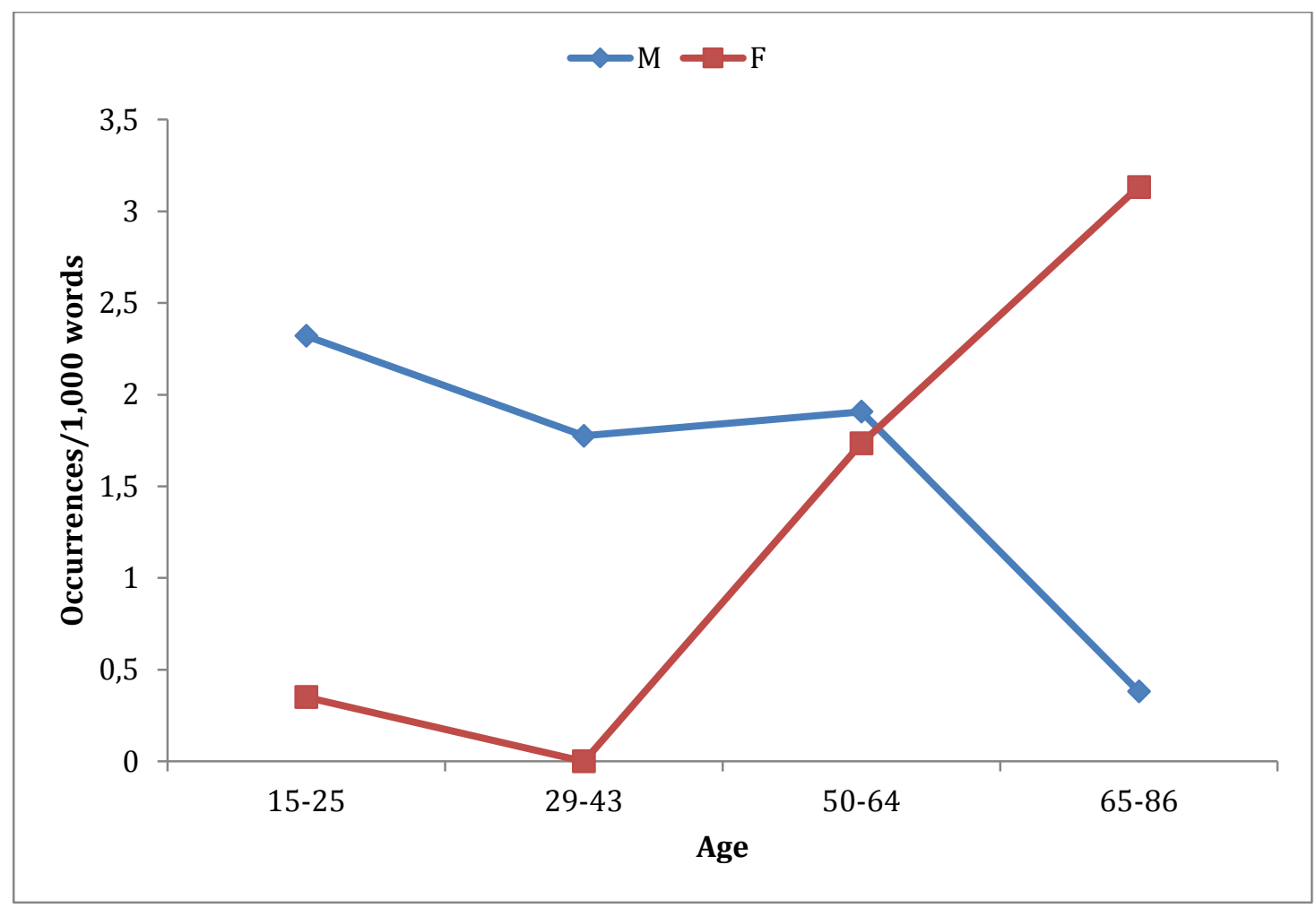

Figure 8: Distribution of the pragmatic marker $e h$ across age and gender.

In light of these results, comment $\mathrm{A}$ by a 36 year old female speaker reveals the negative evaluation of $e h$. While male speakers are increasingly more often adding $e h$ to the repertoire of identity markers of $\mathrm{CE}$, females evaluate this stereotypical feature as negative and are gradually avoiding it more. The statistical results for this pragmatic marker are highly significant $\left(\chi^{2}: 58.431, \mathrm{df}=3, p<0.01\right)$.

The use of like eh is extremely low at around 0.27 uses per 1,000 words. Hence, we cannot make very general statements about this feature. Only four people used it and one person used it four times which was the highest usage by an individual. Nevertheless, this very infrequent pragmatic marker is a stereotype of $\mathrm{CE}$, amounting to the use of this form in a stylized context (see example D).

\section{Discussion}

The analysis shows that we can observe language change in apparent time for TH-fronting as well as for two of the three discourse markers like, eh and like eh discussed here. However, the linguistic features differ in how they are perceived in the community. While informants do not comment on $\mathrm{TH}$-fronting as a feature of $\mathrm{CE}$, the speakers refer overtly to the use of the three pragmatic markers.

Turning first to the discussion of TH-fronting, the results revealed that style shifting is observable but the direction is not clear; i. e., more TH-fronting is used in the text passage than in the interview or the sentence list. However, in Jansen (2012), style is not a significant factor. This difference in significance can be explained by the addition of teenagers in this sample, while the previous study did not include any speakers younger than 22 . We can therefore assume that this social constraint has changed.

When the participants were asked about TH-fronting, they associated this feature with London/Cockney speech but not CE. Hence, these people have already noticed this stereotypical feature of Working Class London English; however, they associate it only with this variety. According to Labov (1972), style as well as social stratification is observed for 
markers but other studies also find a lack of clear style stratification for TH-fronting: Schleef and Ramsammy (2013) find more [f] for $/ \theta /$ in the reading data than in the interview data for London and they refer to Robinson (2005) who finds more TH-fronting in word-list reading than in interviews in Livingston. Similarly, Stuart-Smith, Timmins and Tweedie (2007) find no difference between interview and word-list style in Glasgow. Llamas (2001: 135), on the other hand, describes TH-fronting as salient and an overtly stigmatized feature that carries covert prestige in Middlesbrough. Hence we get a very mixed picture for this variant of the variable $/ \theta$ / across the country.

The finding that TH-fronting is most likely also a traditional feature in CE which is not recognized as part of the CE inventory leaves us with the assumption that the use of this feature for the older speakers is completely unconscious and must be categorized as an indicator. The dramatic increase in this variant among the 15-25 year old speakers makes us assume that indeed we are looking at a marker here now. In the data set, we see a change from a local to a supraregional feature with an additional increase in conscious awareness. Even though TH-fronting is also a local feature, the unexpected occurrence of TH-fronting in wordinitial position triggers salience which influences the increasing use of this feature in CE.

Rácz (2012a) claims that DAR is a somewhat unexpected linguistic feature in speech situations since this is not a feature of more standard-like varieties. Just as DAR is a feature of a restricted area, i. e. the north of England, clause-final like is also restricted to certain varieties, i. e. Irish English, Scottish English and Northern English. It is however not completely clear where $e h$ is found, while like eh seems to be a discourse marker which is restricted to Carlisle. Consequently, in dialect contact situations, the instances of these pragmatic markers is an unexpected episode for speakers from outside the speech community. Kerswill and Williams (2002) report in their comparative study on dialect levelling and diffusion that the clause-final discourse marker like is recessive in the three communities of Reading, Milton Keynes and Hull. They are surprised by the low recognition of clause-final like but due to the results, they claim that the clause-final position is not very prominent. Clause-final like "has a very low recognition rate and [...] low salience. [...] [O]ne reason for its apparent unfamiliarity may lie in the fact that it occurs in a position that may be both prosodically and pragmatically non-prominent" (Kerswill/ Williams 2002: 103). In Carlisle however, the use of clause-final like is a stereotypical feature of the local dialect. In contrast to Kerswill and Williams, I argue that like in this position is indeed salient as it marks the end of the clause and on top of that in Carlisle it carries social meaning. Similarly, eh and like eh are salient as they mark the end of a phrase or clause, respectively.

Rácz's (2012a, 2012b) approach to quantifying salience of phonetic/phonological features is a step closer to explaining this phenomenon; the quantification of sociolinguistic salience of discourse markers does in fact have to be assessed differently as it is often not possible to identify alternating variants. ${ }^{7}$ Nevertheless, there is no reason to restrict the exploration of salience to the phonetic/phonological level and more research is needed which analyses salience of the morphosyntactic and pragmatic/discourse level.

\section{Conclusion}

The concept of salience is still much understudied and indeed must be seen as an umbrella term for related phenomena more than as a well-defined concept. The salience of consonants and vowels must be assessed differently, as does the salience of morphological and discourse features. What has become clear is that we are talking about very vague units when we are trying to find out what causes a feature to be salient, i. e. phonetic distance. The results and discussion of $\mathrm{TH}$-fronting in $\mathrm{CE}$ have shown that salience can vary between levelling and

\footnotetext{
7 This is also an issue for the analysis of syntactic construction like right dislocation (cf. Durham 2011).
} 
diffusion processes and that language internal factors play a role. The approach by Rácz that features which are low in frequency tend to be salient as their occurrence is unexpected seems to be promising and it seems that it can to some extent be applied to the analysis of pragmatic markers. However, we are still at the beginning of understanding the phenomenon of salience in full and much more research is needed, especially on the morphosyntactic and discourse levels and on the effect that frequency can have on the salience of a feature.

\section{References}

Andersen, Gisle (2001): Pragmatic Markers and Sociolinguistic Variation. Amsterdam: John Benjamins.

Armstrong, Aileen M. et al. (1971). The Place-Names of Cumberland. Cambridge: Cambridge University Press.

Atkinson, John (2011): Linguistic Variation and Change in a North-East Border Town. A Sociolinguistic Study of Darlington. University of Newcastle. Unpublished PhD thesis.

Auer, Peter/Barden, Birgit/Grosskopf, Beate (1998): "Subjective and Objective Parameters Determining 'Salience' in Long-Term Dialect Accommodation". Journal of Sociolinguistics 2/2: 163-187.

Barnfield, Kate/Buchstaller, Isabelle (2010): "Intensifiers on Tyneside. Longitudinal Developments and New Trends". English World-Wide 31/3: 252-287.

Bartlett, Joanne (2013): "'Oh I Just Talk Normal Like'. A Corpus-Based, Longitudinal Study of Constituent-Final Like in Tyneside English". Newcastle Working Papers in Linguistics 19/1: 1-21.

Beal, Joan (2007): "'To Explain the Present'. $18^{\text {th }}$ and $19^{\text {th }}$-Century Antecedents of $21^{\text {st }}-$ Century Levelling and Diffusion". In: Pérez-Guerra, Javier et al. (eds.): "Of Varying Language and Opposing Creed". New Insights into Late Modern English. Bern, Lang: 2546.

Beal, Joan (2008): "English Dialects in the North of England. Morphology and Syntax". In: Kortmann, Bernd/Upton, Clive (eds.): Handbook of Varieties. The British Isles. Berlin, de Gruyter: 373-403.

Beal, Joan (2009): "Enregisterment, Commodification and Historical Context: "Geordie" versus "Sheffieldish"". American Speech 84/2: 138-156.

Buchstaller, Isabelle (2004): "Newcomers to the Pool of Quotatives: Like and Go". In: Conejos, Pilar G. et al. (eds.): Current Trends in Intercultural, Cognitive and Social Pragmatics. Sevilla, University of Sevilla Press: 219-240.

Coupland, Nikolas (2009): "Dialect Style, Social Class and Metacultural Performance. The Pantomime Dame". In: Coupland, Nikolas/Jaworksi, Adam (eds.): The New Sociolinguistics Reader. Basingstoke/New York, Palgrave Macmillan: 311-325.

Cukor-Avila, Patricia (2002): "She Say, She Go, She Be Like: Verbs of Quotation over Time in African American Vernacular English". American Speech 77/1: 3-31.

D'Arcy, Alexandra (2005): Like: Syntax and Development. University of Toronto. Unpublished $\mathrm{PhD}$ thesis.

Durham, Mercedes (2011): "Right Dislocation in Northern England. Frequency and Use Perception Meets Reality". English World-Wide 32/3: 257-279.

Ekwall, Eilert (1918): Scandinavians and Celts in the North-West of England. Lund: Gleerup.

Ellis, Alexander John (1889): On Early English Pronunciation. http://www.archive.org /details/onearlyenglishpr00elliuoft, accessed January 26, 2014.

Hickey, Raymond (2000): "Salience, Stigma and Standard". In: Wright, Laura (ed.): The Development of Standard English 1300-1800. Theories, Descriptions, Conflicts. London, Cambridge University Press: 57-72.

Hickey, Raymond (2002): "Ebb and Flow. A Cautionary Tale of Language Change". In: Fanego, Teresa/Mendez-Naya, Belén/Seoane, Elena (eds.): Sounds, Words, Texts, Change. 
Selected Papers from the Eleventh International Conference on English Historical Linguistics (11 ICEHL). Amsterdam, John Benjamins: 105-128.

Jansen, Sandra (2012): Variation and Change in the Cumbrian City Dialect of Carlisle. University of Duisburg-Essen. Unpublished PhD thesis.

Jansen, Sandra (in preparation a): "Discourse Markers as Stereotypes: Disentangling the Functions of like, eh and like eh in Carlisle English".

Jansen, Sandra (in preparation b): "'Aye watts the crack lad. Ow man awez, we gan like' Enregisterment of Dialect as Representation of Home in Social Media". In: Caeners, Torsten/Caeners, Stefanie (eds): Writing Home. Negotiating and Rehearsing 'Home' in Crossmedial Narratives.

Johnson, Daniel E. (2013): Rbrul. http://www.danielezrajohnson.com/rbrul.html, accessed September 10, 2013.

Kerswill, Paul/Williams, Ann (2002): "Salience as Explanatory Factor in Language Change. Evidence from Dialect Levelling in Urban England". In Jones, Mari/Esch, Edith (eds.): Language Change. The Interplay of Internal, External and Extra-Linguistic Factors. Berlin, Mouton de Gruyter: 81-110.

Kerswill, Paul (2003): "Dialect Levelling and Geographical Diffusion in British English". In: Britain, David/Cheshire, Jenny (eds.): Social Dialectology. In Honour of Peter Trudgill. Amsterdam, John Benjamins: 223-243.

Labov, William (1972): Sociolinguistic Patterns. Philadelphia: University of Pennsylvania Press.

Llamas, Carmen (2001): "The Sociolinguistic Profiling of (r) in Middlesbrough English". In: Van de Velde, Hans/Van Hout, Roeland (eds.): 'r-atics. Sociolinguistics, Phonetic and Phonological Characteristics of / $r /$. Special issue of Études et Travaux. Brussels, ILVP: 123-140.

Llamas, Carmen/Watt, Dominic/Johnson, Daniel Ezra (2009): "Linguistic Accommodation and the Salience of National Identity Markers in a Border Town". Journal of Language and Social Psychology 28/4: 381-407.

Luckmann, Katrin (2009): The Pragmatic Marker like in Clause-Final Position. Its Functional and Social Distribution in Irish English. University of Duisburg-Essen. Unpublished MA Thesis.

Meyerhoff, Miriam (1994): "Sounds Pretty Ethnic, eh? A Pragmatic Particle in New Zealand English". Language in Society 23/3: 367-388.

Meyerhoff, Miriam (2006): Introducing Sociolinguistics. London: Routledge.

Miller, James (2008): "Scottish English. Morphology and Syntax". In: Kortmann, Bernd/Upton, Clive (eds.): Varieties of English. The British Isles. Berlin, Mouton de Gruyter: 299-327.

Møller Jensen, Marie (2011): "Salience in Language Change". In: VaLP 2011: Variation and Language Processing 2011. University of Chester. https://sites.google.com/site/valp2011/, accessed January 26, 2014.

News and Star (2012): "Recognise this Cumbrian Tropical Paradise, like eh?" News and Star: January 27, 2012. http://www.newsandstar.co.uk/opinion/reiver/recognise-this-cumbriantropical-paradise-like-eh-1.929070?referrerPath=opinion/reiver, accessed March 1, 2012

Pichler, Heike (2010): "Methods in Discourse Variation Analysis. Reflections on the Way Forward". Journal of Sociolinguistics 14/5: 581-608.

Podesva, Robert J. (2011): "Salience and the Social Meaning of Declarative Contours. Three Case Studies of Gay Professionals". Journal of English Linguistics 39/3: 233-264.

Przedlacka, Joanna (2001): "Estuary English and RP. Some Recent Findings". Studia Anglica Posnaniensia 30: 35-50.

Rácz, Péter (2012a): "Operationalising Salience. Definite Article Reduction in the North of England". English Language and Linguistics 16: 57-79. 
Rácz, Péter (2012b): "Salience in Sociophonetics - A Case Study of Hungarian Hiatus Resolution". In: Kiefer, Ferenc/Bánréti, Zoltán (eds.): Twenty Years of Theoretical Linguistics in Budapest. Budapest, Tinta Publishing House: 109-122.

Ramisch, Heinrich (2007): "English in the Channel Islands". In: Britain, David (ed.): Language in the British Isles. Cambridge, Cambridge University Press: 176-182.

Rickford, John R. (2004): "Implicational Scales". In: Chambers, Jack K./Trudgill, Peter/Schilling-Estes, Natalie (eds.): The Handbook of Language Variation and Change. Oxford, Blackwell: 142-167.

Robinson, Christine (2005): "Changes in the Dialect of Livingston". Language and Literature 14: 181-193.

Schleef, Erik/Ramsammy, Michael (2013): "Labiodental Fronting of $/ \theta /$ in London and Edinburgh: a Crossdialectal Study". English Language and Linguistics 17/1: 25-54.

Schweinberger, Martin (2012): "A Variational Approach towards Discourse Marker LIKE in Irish-English". In: Migge, Bettina/Maire Ni Chiosain (eds.): New Perspectives on Irish English. Amsterdam/New York, John Benjamins: 179-201.

Steele, Hazel (2008): Mechanisms, Motivations and Outcomes of Change in Morley (Leeds) English. University of York. Unpublished $\mathrm{PhD}$ thesis.

Stuart-Smith, Jane/Timmins, Claire/Tweedie, Fiona (2007): "'Talkin' Jockney'? Variation and Change in Glaswegian Accent". Journal of Sociolinguistics 11: 221-260.

Sullivan, Jeremiah (1857): Cumberland \& Westmorland, Ancient and Modern; the People, Dialect, Superstitions and Customs. London: Whittaker and Co.

Tagliamonte, Sali (2012): Variationist Sociolinguistics. Change, Observation, Interpretation. Chichester: Wiley-Blackwell Publishers.

Tagliamonte, Sali/D'Arcy, Alexandra (2004): "He's Like, She's Like. The Quotative System in Canadian Youth". Journal of Sociolinguistics 8/4: 493-514.

Trudgill, Peter (1986): Dialects in Contact. Oxford: Blackwell.

Trudgill, Peter (1988): "Norwich Revisited. Recent Linguistic Changes in an English Urban Dialect". English World-Wide 9/1: 33-49. 